\title{
Fluoride supplements and fluorosis: a meta-analysis
}

\author{
Amid I. Ismail ${ }^{1}$ and \\ Rajesh R. Bandekar ${ }^{2}$ \\ ${ }^{1}$ Department of Cariology, Restorative \\ Sciences, and Endodontics, School of \\ Dentistry, University of Michigan and \\ ${ }^{2}$ Consortium for Health Outcomes, \\ Innovations and Cost-Effectiveness Studies, \\ University of Michigan, Ann Arbor, Michigan, \\ USA
}

Ismail AI, Bandekar RR: Fluoride supplements and fluorosis: a meta-analysis. Community Dent Oral Epidemiol 1999; 27: 48-56. (C) Munksgaard, 1999
Abstract - This paper presents a systematic review of the dental literature that was carried out to investigate whether the regular use of fluoride supplements in non-fluoridated communities during the period of tooth development increases the risk of dental fluorosis. A MEDLINE search was organized for all documents published, in English, between January 1966 and September 1997 using the following key words: fluorosis, dental, fluoride, fluoride supplement or supplements, drop or drops, and tablet or tablets. Twenty-four studies that assessed the development of dental fluorosis in children who had used fluoride supplements earlier in their life were included in this review. Of the 24 studies, 10 were crosssectional/case control studies and four were follow-up studies. These studies had data that allowed a quantitative estimation of the risk of developing dental fluorosis in users of fluoride supplements. The other 10 studies were excluded because they either did not present enough data or had other methodological problems. A qualitative review of the studies found a consistent and strong association between the use of fluoride supplements and dental fluorosis. The meta-analyses of the cross-sectional/case-control studies estimated that the odds ratio of dental fluorosis in users of fluoride supplements compared with non-users ranged between 2.4 and 2.6. The meta-analyses of the follow-up studies estimated that the relative risk in long-term users was between 5.5 and 12.2. This review confirmed that in non-fluoridated communities the use of fluoride supplements during the first 6 years of life is associated with a significant increase in the risk of developing dental fluorosis.
Key words: fluoride supplements; fluorosis; meta-analysis

Amid I. Ismail, Department of Cariology, Restorative Sciences, and Endodontics, School of Dentistry, The University of Michigan, 1011 N. University, D2347, Ann Arbor, Michigan 48109-1078, USA Tel: +1 734647 9190. Fax: +1 7349361597 E-mail: ismailai@umich.edu

Accepted without peer review 9 November 1998
The objective of this paper is to present a systematic review of the dental literature to answer the following question: does the regular use of fluoride supplements in non-fluoridated communities during the period of tooth development increase the risk of dental fluorosis?

In the absence of direct evidence from randomized clinical trials, harm from interventions, such as fluoride products, should be determined following the criteria described by Lilienfeld \& Stolley (1). Specifically, fluoride supplements are considered a risk factor of dental fluorosis if the association between the use of supplements and fluorosis is strong, consistent, and specific; has the correct tem- poral sequence of an exposure preceding the occurrence of disease; is dose-response dependent; and is biologically plausible.

To assess the strength of the association between the use of fluoride supplements and dental fluorosis, measures such as relative risk (RR) or odds ratios (OR) are used (1). The magnitude of these two measures determines the strength of an association between fluoride supplements and fluorosis. For instance, if the value of RR is at least 2.0 (the probability of disease in the exposed group is two times higher than the probability of disease in the unexposed group), then there is a possibility that the association may be causal if the other criteria are 
met as well. An OR estimates the odds of disease in the exposed group relative to the odds of disease in the unexposed group.

In addition to the strength of an association, consistency of an association refers to finding similar trends in several well-designed studies. Because recall error and confounding are associated with measuring the intake of fluoride during the first 6 years of life, replication is a necessary requirement for concluding that there is an association between the ingestion of fluoride supplements and dental fluorosis. One problem encountered in evaluating the consistency of an association is the diversity in the statistical significance of the findings because of small sample sizes and the different designs used in epidemiological studies. To resolve this problem, meta-analytical methods are used to aggregate data from different studies and provide a quantitative estimate of the OR or RR (2). In a meta-analysis, a systematic review of the literature is conducted and studies are included or excluded from the analysis depending on whether they meet the eligibility criteria for inclusion set by the reviewers. The data are combined statistically to provide a quantitative estimate of the size of effect of exposure and risk of disease (2).

The available evidence on dental fluorosis clearly indicates that there is a temporal sequence between exposure to fluoride during the period of tooth development (0-7 years of life) and the development of dental fluorosis (3-5). There is also some evidence that a dose-response relationship exists between the ingestion of fluoride and occurrence of dental fluorosis (6). Children who brushed their teeth and ingested fluoride supplements had a significantly higher risk of developing fluorosis (7) than children who only brushed their teeth with fluoridated dentifrices.

Regarding the biological plausibility of the association between fluoride supplements and dental fluorosis, there is evidence that the presence of fluoride in tissue fluids that surround the developing enamel organ causes several changes in the biochemistry of ameloblasts and their metabolism, and eventually the mineralization of enamel (8). Fluoride causes the retention of proteins such as amelogenins in the tooth structure leading to the formation of hypomineralized enamel (8) that has a different refraction index than sound non-fluorotic enamel. As a result, light reflection through enamel changes resulting in the appearance of white/ chalky areas.

\section{Methods}

To answer the question posed at the beginning of this paper, a systematic analysis of the dental literature and a meta-analysis were conducted to determine the strength of the association between fluoride supplements and dental fluorosis. A MEDLINE search was organized for all studies published, in English, between January 1966 and September 1997. The following key words were used to search for all documents written in the English literature: fluorosis, dental, fluoride, fluoride supplement or supplements, drop or drops, and tablet or tablets. A search for unpublished studies was also carried out using contacts with researchers in the field. Two unpublished studies were located and one of them (which was subsequently published) was used in this review (permission was not obtained for the second paper).

The studies identified by the search were classified into two groups. The first group included cross-sectional/case-control studies where information on use of fluoride supplements was obtained from self-administered questionnaires or interviews with parents. The second group included follow-up studies where data on fluoride use were available for a group of children and the investigators conducted an examination for presence of fluorosis at a later date. Ten cross-sectional/case-control and four follow-up studies were located with enough data to allow for further quantitative analysis (Table 1 and Table 2).

A total of 10 studies were excluded. The reason for the exclusion of each study is summarized in Table 3. Most of the excluded studies did not present enough data to allow inclusion in the metaanalysis. Another reason for exclusion was the lack of external validity of some of the studies that either included a sample with very high prevalence of fluorosis or had too few users of fluoride supplements. In one clinical study of fluoride supplements the children resided in areas where the fluoride concentration in the water was higher than 0.6 mg/L (Table 3).

Evidence tables were prepared for each group of studies. The evidence tables summarized information on the authors, year of publication, method of data collection and age of exposure to fluoride supplements, groups of exposures included in the study, number of children by group, prevalence of fluorosis, odds ratios or relative risks, and $95 \%$ confidence intervals (CI) (except for study by Pendrys \& Katz [3] where 99\% CI were presented). 
Ismail \& Bandekar

Table 1. Risk of fluorosis in users of fluoride supplements: cross-sectional/case-control studies

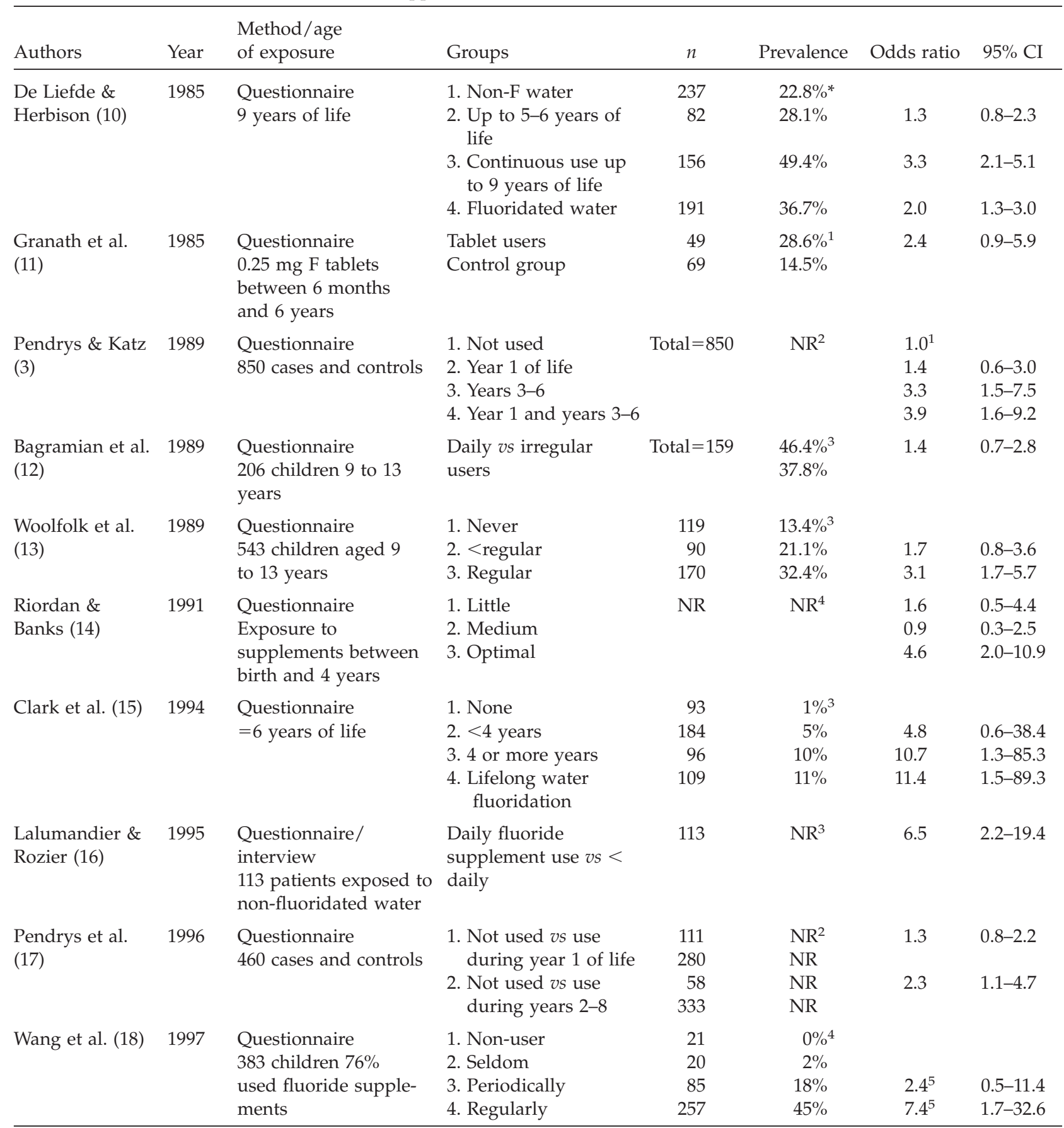

* DDE (Developmental Defects of Enamel) (19): diffuse opacities.

${ }^{1}$ Dean's Fluorosis Index (20).

${ }^{2}$ Fluorosis Risk Index (21): Classification I.

3 TSIF (Tooth Surface Index of Fluorosis) (22).

4 Thylstrup-Fejerskov Fluorosis Index (23).

${ }^{5}$ Compared with those who "seldom" used fluoride supplements.

\section{Meta-analysis}

Any use of fluoride supplements

The first series of meta-analyses that was conducted included all potential users of fluoride supple- ments. The analysis included 10 cross-sectional/ case-control studies and four follow-up studies. The summary odds ratios or relative risks (summary OR or RR) and 95\% confidence intervals were 
obtained using the following three statistical methods:

1) Mantel-Haenszel method: uses $2 \times 2$ frequency tables to estimate the summary OR and its standard error (2).

2) Generalized variance method: uses the calculated OR (or RR) and the lower bound of the 95\% confidence interval to obtain an estimate of the standard error (2).

3) DerSimonian-Laird method: uses $2 \times 2$ frequency tables to estimate the summary OR or RR and its standard error (9). No test of homogeneity is available for this method (2).

The Mantel-Haenszel and the DerSimonian and Laird methods require data from $2 \times 2$ frequency tables to estimate the summary measures (OR or $\mathrm{RR})$ and their standard errors. Twelve $2 \times 2$ tables from the 10 cross-sectional/case-control studies and ten $2 \times 2$ tables from the four follow-up studies were created and used in the meta-analysis. The generalized variance method uses the calculated OR or RR and the lower bound of the $95 \%$ confidence interval (2). For this method, 19 separate odds ratios from the cross-sectional/case-control studies and 11 measures of relative risks were used. Tests of homogeneity of variances for the MantelHaenszel and the generalized variance method were performed as described by Petitti (2).

\section{Appropriate use of fluoride supplements}

The meta-analyses were repeated by including only the users of fluoride supplements who had regularly used fluoride supplementation during at least the first 6 years of life. This condition restricted the number of studies included to seven cross-sectional/case-control studies and four follow-up studies.

\section{Results}

\section{Qualitative review}

Cross-sectional/case-control studies: all users of fluoride supplements

These studies are listed in chronological order in Table 1. Children who used fluoride supplements during the first several years of life had a signi-

Table 2. Risk of fluorosis in users of fluoride supplements: follow-up studies

\begin{tabular}{|c|c|c|c|c|c|c|c|}
\hline Authors & Year & $\begin{array}{l}\text { Method/age } \\
\text { of exposure }\end{array}$ & Groups & $n$ & $\begin{array}{c}\text { Cumulative } \\
\text { incidence }\end{array}$ & $\begin{array}{l}\text { Relative } \\
\text { risk }\end{array}$ & $95 \% \mathrm{CI}$ \\
\hline $\begin{array}{l}\text { Aasenden \& } \\
\text { Peebles (24) }\end{array}$ & 1974 & $\begin{array}{l}\text { Non-randomized } \\
\text { Non-representative } \\
\text { No control for } \\
\text { confounding } \\
\text { Non-fluoridated area }\end{array}$ & $\begin{array}{l}\text { 1. No fluoride } \\
\text { 2. } 0.5 \mathrm{NaF} 0-3 \text { years, } 1.0 \\
\text { afterwards } \\
\text { 3. Fluoridated water }\end{array}$ & $\begin{array}{r}93 \\
100\end{array}$ & $\begin{array}{c}4.3 \% * \\
67 \% \\
32.6 \%\end{array}$ & $\begin{array}{r}15.6 \\
7.6\end{array}$ & $\begin{array}{l}5.9-41.0 \\
2.8-20.7\end{array}$ \\
\hline $\begin{array}{l}\text { Holm \& } \\
\text { Andersson (25) }\end{array}$ & 1982 & $\begin{array}{l}\text { Interviews } \\
\text { Longitudinal study } \\
6 \text { months to } 6 \text { years } \\
\text { Fluorosis was assessed } \\
\text { at the age of } 12 \text { years }\end{array}$ & $\begin{array}{l}\text { Age at start of use of } \\
\text { NaF tablets (months): } \\
\text { 1. } 6 \\
\text { 2. } 12 \\
\text { 3. } 24 \\
\text { 4. } 36 \\
\text { 5. Sporadically } \\
\text { 6. Not }\end{array}$ & $\begin{array}{r}21 \\
51 \\
8 \\
6 \\
28 \\
20\end{array}$ & $\begin{array}{l}81 \%^{+} \\
59 \% \\
38 \% \\
33 \% \\
18 \% \\
15 \%\end{array}$ & $\begin{array}{l}5.4 \\
3.9 \\
2.5 \\
2.2 \\
1.2 \\
1.0\end{array}$ & $\begin{array}{l}1.9-15.6 \\
1.4-11.4 \\
0.6-9.9 \\
0.5-10.4 \\
0.3-4.4\end{array}$ \\
\hline Larsen et al. (26) & 1985 & $\begin{array}{l}70 \text { children who } \\
\text { received } 0.5 \mathrm{mg} \text { F tablet/ } \\
\text { day between } 2.5 \text { and } 9.4 \\
\text { years; } 40 \text { children with } \\
\text { no tablets } \\
\text { Blind examinations }\end{array}$ & $\begin{array}{l}\text { Central incisors } \\
\text { 1. 2.5-4.4 years } \\
\text { 2. 4.5-9.4; no tablets } \\
\text { Lateral incisors } \\
\text { 1. 2.5-4.4 } \\
\text { 2. 4.5-9.4; no tablets }\end{array}$ & $\begin{array}{l}20 \\
84 \\
19 \\
82\end{array}$ & $\begin{array}{c}15 \%^{+} \\
3.6 \% \\
15.8 \% \\
3.7 \%\end{array}$ & 4.2 & 0.9-19.3 \\
\hline Kalsbeek et al. (6) & 1992 & $\begin{array}{l}\text { Dentists evaluated use } \\
\text { of supplements between } \\
1.5 \text { anf } 6 \text { years; fluorosis } \\
\text { was assessed at the age } \\
\text { of } 15 \text { years }\end{array}$ & $\begin{array}{l}\text { 1. Not a user } \\
\text { 2. Irregular user } \\
\text { 3. Regular user } \\
\text { 4. Frequent user }\end{array}$ & $\begin{array}{r}55 \\
125 \\
179 \\
61\end{array}$ & $\begin{array}{l}7 \%^{+} \\
10 \% \\
19 \% \\
36 \%\end{array}$ & $\begin{array}{l}1.4 \\
2.6 \\
5.0\end{array}$ & $\begin{array}{l}0.5-4.2 \\
1.0-7.0 \\
1.8-13.5\end{array}$ \\
\hline
\end{tabular}

\footnotetext{
* Dean's Fluorosis Index (20): very mild to moderate fluorosis.

+ Thylstrup-Fejerskov Fluorosis Index (23).
} 
ficant increase in the risk of developing dental fluorosis. Eight studies found statistically positive associations between the use of fluoride supplements and dental fluorosis (Table 1). The OR of developing fluorosis in users of fluoride supplements during the first 8 years of life ranged from a low of 1.3 to a high of 10.7 .

Follow-up studies: all users of fluoride supplements These studies are listed in chronological order in Table 2. The relative risk of developing fluorosis in children who used fluoride supplements during the first several years of life was highly significant $(\mathrm{RR}=15.6$ with $95 \% \mathrm{CI}=5.9-41.0$ [24] or $\mathrm{RR}=5.0$ with $95 \% \mathrm{CI}=1.8-13.5$ [6]). One study found that the earlier in life fluoride supplements were used the higher the risk of developing fluorosis (25).
Children who started using fluoride supplements at the age of 6 months had 5.4 times higher incidence of dental fluorosis than children who did not use supplements at all (25). The use of fluoride supplements during the first year of life is associated with a statistically significant increase in risk of fluorosis (Table 2). Children who used supplements starting at the age of 24 months had an increased risk compared to non-users, but the RR was not statistically significant because of the small sample size (25). In another small study, children who used fluoride supplements between 2.5 and 4.4 years of their lives had a higher relative risk (4.2) than children who either did not use supplements or used them after the age of 4.4 years (26). This finding was not statistically significant because of the small sample size (95\% CI: 0.9-19.3).

Table 3. List of excluded studies

\begin{tabular}{|c|c|c|}
\hline Author & Year & Finding \\
\hline Hennon et al. (27) & 1977 & $\begin{array}{l}\text { A randomized clinical trial with significant loss } \\
\text { of subjects. Children who used } 0.5 \mathrm{mg} \mathrm{F} \\
\text { supplements between } 0-3 \text { years and } 1.0 \mathrm{mg} \mathrm{F} \\
\text { supplements between } 3 \text { and } 6.5 \text { years had } \\
\text { significantly higher incidence of fluorosis } \\
\text { compared with children who were on a placebo }\end{array}$ \\
\hline $\begin{array}{l}\text { Thylstrup et al. } \\
\text { (28) }\end{array}$ & 1979 & $\begin{array}{l}\text { "A positive association between number of } \\
\text { tablets prescribed and dental fluorosis was found } \\
\text { in erupted permanent teeth" }\end{array}$ \\
\hline Allmark et al. (29) & 1982 & $\begin{array}{l}\text { No differences in fluorosis between children } \\
\text { who sucked } 2.2 \mathrm{mg} \mathrm{NaF} \text { tablets and those in the } \\
\text { control group. Program started at the age of } 6 \\
\text { years }\end{array}$ \\
\hline
\end{tabular}

Wöltgens et al. (7) 1989 Daily fluoride intake before the age of 4 years may explain the high prevalence of "mottled" enamel

Kumar et al. (30) 1989 Daily use of fluoride tablets increased the risk of fluorosis

Ismail et al. (31) 1990 "The use of fluoride supplements was significantly associated with fluorosis". Odds ratio $=1.8(1.5-2.1)$

Holt et al. (32) 1990 "There was a statistically insignificant, but consistent, trend for the prevalence of opacities to increase with increasing duration of use of fluoride supplements"

Stephen et al. (33) 1991 No significant difference between children who used fluoride supplement at birth and those who had started at the age of 7 years

D’Hoore \& Van Nieuwenhuysen (34)

Riordan (35)
1992 Children who used fluoride tablets exhibited mild fluorosis more frequently than non-users. Odds ratio $=9.6$

1993 Supplement use did not afftect caries or fluorosis prevalences
Reason for exclusion

The children in the study resided in area that had $0.6-0.8 \mathrm{mg} / \mathrm{L}$ fluoride in its drinking water

Statistics included in the paper were not sufficient to estimate the risk of fluorosis

Not applicable to 0-6-year-old age group

Inadequate data were presented

Inadequate data were presented

Data were not presented separately for the fluoridated and non-fluoridated communities

Only summary data were presented. The prevalence of fluorosis in the children who did not use fluoride supplements was $>60 \%$

Inadequate data were presented on fluorosis and use of fluoride supplements

Inadequate data were presented on fluorosis and use of fluoride tablets

Fluoride supplements were used by only $4.6 \%$ of the children in the study 
Table 4. Findings from the meta-analysis that included all users of fluoride supplements

\begin{tabular}{|c|c|c|c|c|c|}
\hline Study type & $\begin{array}{l}\text { Number of } \\
2 \times 2 \text { tables }\end{array}$ & Methods & $\begin{array}{l}\text { Summary } \\
\text { OR or RR }\end{array}$ & $95 \% \mathrm{CI}$ & $\begin{array}{c}\text { Test of } \\
\text { homogeneity } \\
\left(\chi^{2} \text { value, } P \text {-value }\right)\end{array}$ \\
\hline \multirow{3}{*}{$\begin{array}{l}\text { Cross-sectional/ } \\
\text { case control }\end{array}$} & 12 & Mantel-Haenszel & 2.3 & $(1.5,3.4)$ & $(12.1,0.4)$ \\
\hline & 19 & Generalized variance & 2.2 & $(1.9,2.6)$ & $(34.2,0.01)$ \\
\hline & 12 & DerSimonian-Laird & 2.1 & $(1.7,2.5)$ & NA \\
\hline \multirow[t]{3}{*}{ Follow-up* } & 10 & Mantel-Haenszel & 6.6 & $(2.9,15.2)$ & $(15.2,0.08)$ \\
\hline & 11 & Generalized variance & 1.3 & $(2.6,5.3)$ & $(16.6,0.08)$ \\
\hline & 10 & DerSimonian-Laird & 3.5 & $(2.3,5.5)$ & NA \\
\hline
\end{tabular}

$\mathrm{NA}=$ not applicable.

* Generalized variance estimate, confidence interval and test of homogeneity are based on the RR.

\section{Meta-analysis}

Cross-sectional/case-control studies: all users of fluoride supplements

Table 4 presents the findings of several meta-analyses using the previously described methods. The Mantel-Haenszel method estimated that the summary OR for the association between any use of fluoride supplements and dental fluorosis is about 2.3 (95\% confidence interval: 1.5-3.4). The DerSimonian-Laird and generalized variance methods gave a summary OR of $2.1(1.7-2.5)$ and $2.2(1.9-$ 2.6), respectively. Because of the lack of homogeneity of variances among the studies, the results of the Mantel-Haenszel method, which assumes equality of the variances of the odds ratios, may be invalid. The random-effect method that is the basis for the DerSimonian-Laird algorithm is preferred in this case. However, the DerSimonian-Laird method gives higher weight to small studies and hence, it may emphasize poor evidence at the expense of good evidence (2). Overall, the meta-analyses found that the summary OR on average is between 2.1 and 2.3, indicating that children who use fluoride supplements have two times higher odds of developing fluorosis than those who never used fluoride supplements.

Follow-up studies: all users of fluoride supplements For the follow-up studies, the summary RR ranged between 1.3 (2.6-5.3) for the generalized variance method and 6.6 (2.9-15.2) for the Mantel-Haenszel method. The DerSimonian-Laird method estimated that the summary RR was 3.5 (2.3-5.5). The followup studies showed a stronger association between any use of fluoride supplements and dental fluorosis because the determination of exposure to fluoride supplements was based on records or detailed interviews rather than recall by parents or self-administered questionnaires.

\section{Appropriate use of fluoride supplements}

When the meta-analyses were restricted to children who had regularly used fluoride supplements during at least the first 6 years of life (Table 5), the summary OR were between 2.4 and 2.6 (Table 5). For the follow-up studies, the DerSimonian-Laird

Table 5. Findings from the meta-analysis that included appropriate users of fluoride supplements (during at least the first 6 years of life)

\begin{tabular}{|c|c|c|c|c|c|}
\hline Study type & $\begin{array}{l}\text { Number of } \\
2 \times 2 \text { tables }\end{array}$ & Methods & $\begin{array}{l}\text { Summary } \\
\text { OR or RR }\end{array}$ & $95 \% \mathrm{CI}$ & $\begin{array}{c}\text { Test of } \\
\text { homogeneity } \\
\left(\chi^{2} \text { value, } P \text {-value }\right)\end{array}$ \\
\hline \multirow{3}{*}{$\begin{array}{l}\text { Cross-sectional/ } \\
\text { case control }\end{array}$} & 7 & Mantel-Haenszel & 2.6 & $(1.7,4.1)$ & $(6.1,0.4)$ \\
\hline & 12 & Generalized variance & 2.6 & $(2.1,3.2)$ & $(23.9,0.01)$ \\
\hline & 7 & DerSimonian-Laird & 2.4 & $(1.9,3.1)$ & NA \\
\hline \multirow[t]{3}{*}{ Follow-up* } & 5 & Mantel-Haenszel & 12.2 & $(4.9,30.4)$ & $(7.2,0.13)$ \\
\hline & 5 & Generalized variance & 5.6 & $(3.4,9.4)$ & $(11.8,0.02)$ \\
\hline & 5 & DerSimonian-Laird & 5.5 & $(2.7,11.4)$ & NA \\
\hline
\end{tabular}

NA $=$ not applicable.

* Generalized variance estimate, confidence interval and test of homogeneity are based on the RR. 
method estimated a summary OR of 5.5 (2.7-11.4) (Table 5), which is higher than the 3.5 reported in the previous analysis (Table 4).

\section{Discussion}

This qualitative and quantitative review found that the use of fluoride supplements increases the risk of developing dental fluorosis by at least two times. Most of the fluorosis found in the studies included in this paper was of the very mild to mild type. The association between fluoride supplements and dental fluorosis is strong and consistent. There is a clear temporal sequence in that infants and toddlers who used fluoride supplements had a higher prevalence of fluorosis in their permanent teeth than those who did not use fluoride supplements. This finding was recently confirmed by an epidemiological study of a population that was exposed to about $3.0 \mathrm{mg} / \mathrm{L}$ naturally fluoridated water for a period of 7 years (5). Children who were not born or were less than 1 year old when the drinking water of the community was switched from a low- to a high-fluoride source experienced the highest levels of fluorosis compared with older children (5). The odds that a child who had used the high fluoride water during the first year of life developed dental fluorosis was 2.5 times higher than those of children who drank the same water after the age of 2 years (5).

The specificity of the association between dental fluorosis and the use of fluoride supplements is difficult to establish from epidemiological studies that rely on recall of past use of fluoride products. There is evidence that the combined use of fluoride supplements and toothbrushing with a fluoridated dentifrice during the first year of life significantly increases the odds of developing fluorosis $(\mathrm{OR}=$ 6.2) compared with toothbrushing alone $(\mathrm{OR}=1.5)$ (4). Hence, fluoride supplements have at least an additive effect on the risk of developing dental fluorosis in infants and toddlers who brush their teeth with fluoridated dentifrices.

In addition to the finding of this analysis there are other issues that need to be considered when prescribing supplements. The problem with getting professionals to comply with the current dosage schedules for use of fluoride supplements is an important factor to consider in assessing this vehicle for delivery of fluoride. There is now consistent evidence to support the observation that some health professionals prescribe fluoride supplements without taking into account the level of fluoride in the drinking water (36).
In addition, there are other sources of exposure to fluoride during infancy that have not yet been considered in the current guidelines for use of fluoride supplements. The use of soy-based milk formulae and tea raises the fluoride intake of some infants to "near optimal levels" (37). Infants' foods and drinks may also contain enough fluoride to provide the so called "optimal intake" (38). Considering these factors, it is imperative that new guidelines for fluoride supplements either take the total intake of fluoride of children into account or consider their caries risk status before recommending fluoride supplements.

While this paper did not address the question of the pre- and post-eruptive effects of fluoride on caries prevention, the other papers presented at this conference $(39,40)$ clearly show that fluoride works best when available in low concentrations in the oral environment for long periods during a day. The topical effect of fluoride on development of dental caries was documented over 50 years ago by Klein (41) who found a decline of $40 \%-60 \%$ between 1943 and 1945 in dental caries incidence among Japanese-American children who were forced to live in a detention camp, during World War II, that had a naturally fluoridated water (3.0 $\mathrm{mg} / \mathrm{L}$ ) compared with another group of JapaneseAmerican children who were located to a lowfluoride camp. The effect of fluoride on protecting newly erupting teeth was higher than the effect on teeth that had erupted before the relocation to the detention camps (41). These findings closely parallel those reported in the water fluoridation studies and experiments conducted in the 1940s and 1950s (42).

Policy-makers should consider these factors when making a decision on new recommendations for fluoride supplements. It is important to weigh in the risks and benefits of using systemic fluoride supplements in infants and toddlers. Physicians and dentists need to consider that there are two well-established and accepted methods for caries prevention in our communities: water fluoridation and toothbrushing with fluoridated pastes or gels. An infant or toddler who brushes at least once a day receives a dose of systemic fluoride (43). Given the increased risk of dental fluorosis that could result from the combined use of fluoridated dentifrices and fluoride supplements, it is imperative and ethically necessary that health professionals consider the total exposure to fluoride in deciding whether to recommend fluoride supplements. Fluoride supplements should be targeted for 
infants and toddlers who, in the clinical opinion of a health professional, are at risk of developing dental caries. While the accuracy of the professional assessment of caries risk has not yet been studied, there is ample evidence that dental caries clusters in families with low socioeconomic and education status (44). Infants of mothers who are not concerned about the sugar intake levels of their infants should also be considered at high risk of developing dental caries (45). Mothers with a history of caries development are more likely to infect their children with cariogenic bacteria and put their infants and toddlers at increased risk of developing early childhood caries (46).

This analysis clearly shows that the use of fluoride supplements increases the risk of developing dental fluorosis. Though the severity of fluorosis in the large majority of children is very mild, dentists should inform the parents about the risks and benefits that are associated with the use of fluoride supplements. For many children, there may not be a need for an additional application of fluoride. For some children, the detrimental effect of a rampant caries attack outweighs the risk of developing dental fluorosis. For such children, an additional source of fluoride (in the form of drops and tablets that are chewed and swished in the mouth) may be beneficial.

\section{References}

1. Lilienfeld DE, Stolley PD. Foundations of epidemiology. New York: Oxford Univ Pr; 1994. p. 263-8.

2. Petitti DB. Meta-analysis, decision analysis and cost-effectiveness analysis. Methods for quantitative synthesis in medicine. New York: Oxford Univ Pr; 1994. p. 90-123.

3. Pendrys DV, Katz RV. Risk of enamel fluorosis associated with fluoride supplementation, infant formula, and fluoride dentifrice. Am J Epidemiol 1989;130:1199-208.

4. Osuji OO, Leake JL, Chipman ML, Nikiforuk G, Locker D, Levine N. Risk factors for dental fluorosis in a fluoridated community. J Dent Res 1988;67:1488-92.

5. Ismail AI, Messer JG. The risk of fluorosis in students exposed to a higher than optimal concentration of fluoride in well water. J Public Health Dent 1996;56:22-7.

6. Kalsbeek H, Verrips GH, Backer Dirks O. Use of fluoride tablets and effect on prevalence of dental caries and dental fluorosis. Community Dent Oral Epidemiol 1992;20:241-5.

7. Wöltgens JHM, Etty EJ, Nieuwland WMD, Lyaruu DM. Use of fluoride by young children and prevalence of mottled enamel. Adv Dent Res 1989;3:177-82.

8. Limeback H. Enamel formation and the effects of fluoride. Community Dent Oral Epidemiol 1994;22:144-7.

9. DerSiomnian R, Laird N. Meta-analysis in clinical trials. Control Clin Trials 1986;7:177-88.

10. De Liefde B, Herbison GP. Prevalence of developmental defects of enamel and dental caries in New Zealand chil- dren receiving differing fluoride supplementation. Community Dent Oral Epidemiol 1985;13:164-17.

11. Garnath L, Widenheim J, Birkhed D. Diagnosis of mild enamel fluorosis in permanent maxillary incisors using two scoring systems. Community Dent Oral Epidemiol 1985;14;273-6.

12. Bagramian RA, Narendran S, Ward M. Relationship of dental caries and fluorosis to fluoride supplement history in a non-fluoridated sample of schoolchildren. Adv Dent Res 1989;3;161-7.

13. Woolfolk MW, Faja BW, Bagramian RA. Relation of sources of systemic fluoride to prevalence of dental fluorosis. J Public Health Dent 1989;49:78-82.

14. Riordan PJ, Banks JA. Dental fluorosis and fluoride exposure in Western Australia. J Dent Res 1991;70:1022-8.

15. Clark DC, Hann HJ, Williamson MF, Berkowitz J. Influence of exposure to various fluoride technologies on the prevalence of dental fluorosis. Community Dent Oral Epidemiol 1994;22:461-4.

16. Lalumandier JA, Rozier GA. The prevalence and risk factors of fluorosis among patients in a pediatric dental practice. Pediatr Dent 1995;17:19-25.

17. Pendrys DG, Katz R, Morse DE. Risk factors for enamel fluorosis in nonfluoridated communities. Am J Epidemiol 1996;143:808-15.

18. Wang NJ, Gropen A-M, Øgaard B. Risk factors associated with fluorosis in a non-fluoridated population in Norway. Community Dent Oral Epidemiol 1997;25:396-401.

19. Fédération Dentaire Internationale. An epidemiologic index of developmental defects of dental enamel (DDE). Tech Rep No. 15. London: FDI; 1982.

20. Dean HT. The investigation of physiological effects by the epidemiological method. In: Moulton FE, editor. Fluoride and dental health. Washington (DC): American Association for the Advancement of Science; 1942. p. 23-31.

21. Pendrys DG. The Fluorosis Risk Index: a method for investigating risk factors. J Public Health Dent 1990;50:2918.

22. Horowitz HS, Driscoll WS, Meyers RJ, Heifetz SB, Kingman A. A new method for assessing the prevalence of dental fluorosis: the Tooth Surface Index of Fluorosis. J Am Dent Assoc 1984;109:34-41.

23. Thylstrup A, Fejerskov O. Clinical appearance of dental fluorosis in permanent teeth in relation to histologic changes. Community Dent Oral Epidemiol 1978;6:31528.

24. Aasenden R, Peebles TC. Effects of fluoride supplementation from birth on human deciduous and permanent teeth. Arch Oral Biol 1974;19:321-6.

25. Holm A-K, Andersson R. Enamel remineralization disturbances in 12-year-old children with known early exposure to fluoride. Community Dent Oral Epidemiol 1982;10;335-9.

26. Larsen MJ, Richards A, Fejerskov O. Development of dental fluorosis according to age at start of fluoride supplementation. Caries Res 1985;19:519-27.

27. Hennon DK, Stookey GK, Beiswanger BB. Fluoride-vitamin supplements: effects on dental caries and fluorosis when used in areas with suboptimum fluoride in the water supply. J Am Dent Assoc 1977;95:965-71.

28. Thylstrup A, Fejerskov O, Bruun C, Kann J. Enamel changes and dental caries in 7-year-old children given fluoride tablets from shortly after birth. Caries Res 1979;13:265-76.

29. Allmark C, Green HP, Linney AD, Wills DJ, Picton DCA. A community study of fluoride tablets for school children in Portsmouth. Br Dent J 1982;153:426-30. 
30. Kumar JV, Green EL, Wallace W, Carnahan T. Trends in dental fluorosis and dental caries prevalences in Newburgh and Kingston, NY. Am J Public Health 1989;79:565-9.

31. Ismail AI, Brodeur J-M, Kavanagh M, Boisclair G, Tessier C, Picotte L. Prevalence of dental caries and dental fluorosis in students, 11-17 years of age, in fluoridated and non-fluoridated cities in Quebec. Caries Res 1990;24:2907.

32. Holt RD, Winter GB, Fox B, Askew R. Enamel opacities in children whose mothers took part in a dental health education scheme. Community Dent Oral Epidemiol 1990;18:74-6.

33. Stephen KW, McCall DR, Gilmour WH. Incisor enamel mottling prevalence in child cohorts which had or had not taken fluoride supplements from 0-12 years of age. Proc Finn Dent Soc 1991;87:595-605.

34. D'Hoore W, Van Nieuwenhuysen J-P. Benefits and risks of fluoride supplementation: caries prevention versus dental fluorosis. Eur J Pediatr 1992;151:613-6.

35. Riordan PJ. Dental fluorosis, dental caries and fluoride exposure among 7-year-olds. Caries Res 1993;27:71-7.

36. Pendrys DG, Morse DE. Use of fluoride supplementation by children living in fluoridated communities. J Dent Child 1990;57:343-7.

37. Chowdhury NG, Brown RH, Shepherd MG. Fluoride intake of infants in New Zealand. J Dent Res 1990;69:182833.

38. Heilman JR, Kiritsy MC, Levy SM, Wefel JS. Fluoride concentrations of infant foods. J Am Dent Assoc 1997;128:857-63.

39. Featherstone JP. A review of the biological mechanism of how low daily doses of fluoride cause dental fluorosis. Community Dent Oral Epidemiol, submitted, 1998.

40. DenBesten P. A review of the evidence that fluoide supplements are a primary risk factor of dental fluorosis in non-fluoridated areas. Community Dent Oral Epidemiol, submitted, 1998.

41. Klein H. Dental caries (DMF) experience in relocated children exposed to water containing fluorine. II. J Am Dent Assoc 1946;33:1136-41.

42. Brown HK, Popove M. Brantford-Sarnia-Stratford fluoridation caries study: final survey, 1963. J Can Dent Assoc 1965;31:505-11.

43. Harrison R, Wong T, Ewan C, Contreras B, Phung Y. Feeding practices and dental caries in an urban Canadian population of Vietnamese preschool children. J Dent Child 1997;64:112-7.

44. Reisine S, Litt M . Social and psychological theories and their use for dental practice. Int Dent J 1993; 43(Suppl): 279-87.

45. Kohler B, Bratthall D, Krasse B. Preventive measures in mothers influence the establishment of the bacterium Streptococcus mutans in their infants. Arch Oral Biol 1983;28:225-31.

46. Levy SM, Kiritsy MC, Slager SL, Warren JJ, Kohout FJ. Patterns of fluoride dentifrice use among infants. Pediatr Dent 1997;19:50-5. 